\title{
Research Square \\ Real-World Pharmacokinetics and \\ Pharmacodynamics of Everolimus in Metastatic Breast Cancer
}

\section{Masahide Fukudo ( $\square$ fukudom@sapmed.ac.jp )}

Sapporo Medical University: Sapporo Ika Daigaku https://orcid.org/0000-0002-7703-7827

\section{Kei Ishibashi}

Asahikawa Medical University: Asahikawa Ika Daigaku

Masahiro Kitada

Asahikawa Medical University: Asahikawa Ika Daigaku

\section{Research Article}

Keywords: Everolimus, Pharmacokinetics, Pharmacodynamics, Therapeutic drug monitoring, Breast cancer

Posted Date: May 4th, 2021

DOl: https://doi.org/10.21203/rs.3.rs-449602/v1

License: (c) (i) This work is licensed under a Creative Commons Attribution 4.0 International License. Read Full License 


\section{Abstract}

\section{Purpose}

This study investigated the relationship between the pharmacokinetics and pharmacodynamics of everolimus in patients with metastatic breast cancer $(\mathrm{mBC})$ in real-world practice.

\section{Methods}

Twenty-two patients with $\mathrm{mBC}$ treated with everolimus plus exemestane were enrolled. Blood everolimus concentrations were measured at outpatient visits. The inhibition of the mammalian target of rapamycin (mTOR) activity in peripheral blood mononuclear cells (PBMCs) was examined. The efficacy and safety endpoints were progression-free survival (PFS) and the cumulative incidence of dose-limiting toxicities (DLTs), respectively.

\section{Results}

Blood samples were obtained from 19 consenting patients. Everolimus did not completely inhibit mTOR activity in PBMCs at therapeutic concentrations ( $56 \%$ maximal inhibition). The most common adverse event was stomatitis (any grade $77 \%)$. The trough concentration $\left(C_{\text {trough }}\right)$ was significantly higher in patients experiencing DLTs than in those without any DLTs $(P=0.030)$. The optimal $\mathrm{C}_{\text {trough }}$ cutoff predicting DLT development was $17.3 \mathrm{ng} / \mathrm{mL}$. The cumulative incidence of DLTs was significantly higher in patients with $C_{\text {trough }} \geq 17.3 \mathrm{ng} / \mathrm{mL}$ than in other patients (sub-hazard ratio $4.87,95 \%$ confidence interval $[\mathrm{Cl}] 1.53-15.5 ; P=0.007)$. Furthermore, the median PFS was numerically longer in patients who

maintained a steady-state $C_{\text {trough }}$ below the threshold than in those who did not (327 days [95\% Cl 103355 days] vs 194 days [95\% $\mathrm{Cl} 45$ days-not estimable]; $P=0.35$ ).

\section{Conclusion}

The suggested upper threshold for the therapeutic window of everolimus $C_{\text {trough }}$ was $17.3 \mathrm{ng} / \mathrm{mL}$. Pharmacokinetically guided dosing may improve the efficacy and safety of everolimus for $\mathrm{mBC}$, warranting further investigation in a larger study.

\section{Introduction}

Everolimus, an orally active inhibitor of the mammalian target of rapamycin (mTOR), has been used as an immunosuppressive drug in solid organ transplantation [1]. Based on its antiangiogenic and antitumor activity, everolimus has been approved as single-agent therapy for advanced renal cell carcinoma (RCC), neuroendocrine tumors (NET) of pancreatic, gastrointestinal, or lung origin, and tuberous sclerosis complex (TSC)-associated subependymal giant cell astrocytoma (SEGA) as well as TSC-associated renal angiomyolipoma [2-5]. Everolimus is also used in combination with exemestane to treat hormone 
receptor-positive, human epidermal growth factor receptor 2 (HER2)-negative metastatic breast cancer $(\mathrm{mBC})$ after progression on nonsteroidal aromatase inhibitors [6].

Everolimus has a narrow therapeutic index and shows significant inter-individual pharmacokinetic variability when used as an immunosuppressant; therefore, routine therapeutic drug monitoring (TDM) is recommended to maintain a target blood everolimus trough concentration $\left(\mathrm{C}_{\text {trough }}\right)$ between 3 and 8 $\mathrm{ng} / \mathrm{mL}[7,8]$. On the other hand, for the treatment of TSC-associated SEGA only, the dose is adjusted based on TDM to attain a $C_{\text {trough }}$ of $5-15 \mathrm{ng} / \mathrm{mL}$ [9]. The approved dosage of everolimus for other oncological indications is $10 \mathrm{mg}$ orally once daily. This fixed dosing schedule is associated with clinically relevant toxicities, including severe stomatitis and non-infectious pneumonitis, which often necessitates dose modifications.

Everolimus is absorbed relatively rapidly, and the maximum drug concentration is reached between 1 to 2 h post-dose [10]. Everolimus is metabolized primarily in the gut and liver by cytochrome P450 (CYP) 3A4, $3 A 5$, and $2 \mathrm{C} 8$ [10]. While everolimus is a substrate for the efflux pump P-glycoprotein (P-gp/ABCB1), it also inhibits P-gp and breast cancer resistance protein (BCRP/ABCG2) [11-13]. Genetic polymorphisms in genes encoding these drug-metabolizing enzymes and efflux transporters have no clinically relevant influence on everolimus pharmacokinetics in transplant recipients; however, the potential effects have not been fully characterized in cancer patients [14-18].

Regarding pharmacodynamics, everolimus binds to the intracellular FK506-binding protein 1A (FKBP1A) with two-fold less affinity than tacrolimus (FK506) [19]. This complex inhibits the kinase activity of mTOR, which inactivates the downstream p70S6 kinase (S6K) and increases the inhibitory binding of eukaryotic translation initiation factor $4 \mathrm{E}$ (elF4E)-binding protein 1 (4E-BP1) to elF4E; together these actions inhibit cell growth and metabolism as well as cell proliferation and survival [20]. It has been shown that the degree of inhibition of p70S6 kinase is identical in peripheral blood mononuclear cells (PBMCs) and simultaneously collected tumor tissue in cancer patients receiving $\mathrm{CCl}-779$, another mTOR inhibitor, suggesting that PBMCs are a valid surrogate tissue for the pharmacodynamic monitoring of mTOR inhibitors in vivo [21].

The objectives of this study were as follows: (1) to characterize the pharmacokinetics and pharmacodynamics of everolimus in patients with $\mathrm{mBC}$; (2) to investigate the potential impact of pharmacogenetics on everolimus exposure; and (3) to clarify the relationship between everolimus exposure and clinical outcomes in real-world practice.

\section{Patients And Methods}

\section{Study design and patients}

We conducted a single-center, prospective cohort study in the context of routine clinical practice rather than a clinical trial, with the aim of optimizing everolimus dosing through pharmacokinetic and pharmacodynamic analysis in patients with $\mathrm{mBC}$. The protocol was approved by the institutional ethics 
committee of Asahikawa Medical University (\#14085). Written informed consent was obtained from each patient prior to participation in the study. Consecutive patients with $\mathrm{mBC}$ who started everolimus plus exemestane between June 2014 and December 2019 were prospectively enrolled. The baseline characteristics of the patients are summarized in Table 1.

\section{Treatment}

Everolimus was administered orally at $10 \mathrm{mg}$ once daily in combination with exemestane $(25 \mathrm{mg}$ orally once daily). When severe adverse events were present, the everolimus dose was temporarily reduced or interrupted, followed by resumption at a reduced dose. Everolimus treatment was continued until the occurrence of disease progression, unacceptable toxicity, or patient refusal.

\section{Blood samples}

In the outpatient setting, we obtained blood samples immediately before each patient's morning dose to measure individual everolimus $\mathrm{C}_{\text {trough }}$ levels (i.e., $\mathrm{C}_{0}$ ). Otherwise, blood samples were routinely collected from remnant blood specimens after laboratory testing at each visit. These nontrough blood samples, taken within approximately $4 \mathrm{~h}$ after the morning dose, were used to measure individual everolimus peak concentrations $\left(C_{\text {peak }}\right)$. Blood samples for the concentrations $C_{1}, C_{2}, C_{3}$, and $C_{4}$ were defined as those obtained at $1 \mathrm{~h} \pm 30 \mathrm{~min}, 2 \mathrm{~h} \pm 30 \mathrm{~min}, 3 \mathrm{~h} \pm 30 \mathrm{~min}$, and $4 \mathrm{~h} \pm 30 \mathrm{~min}$ post-dose, respectively. Additionally, blood samples taken in the post-absorption phase at $12 \pm 2 \mathrm{~h}$ and $24 \pm 2 \mathrm{~h}$ post-dose were used to determine $\mathrm{C}_{12}$ and $\mathrm{C}_{24}$, respectively.

\section{Pharmacokinetic assessment}

Whole blood samples $(150 \mu \mathrm{L})$ were deproteinized with $450 \mu \mathrm{L}$ of methanol/0.2 $\mathrm{M} \mathrm{ZnSO}_{4}(70 / 30, \mathrm{v} / \mathrm{v})$ containing the internal standard ascomycin. After vortex and centrifugation, the supernatant was treated with solid-phase extraction using Oasis HLB cartridges (Waters, Tokyo, Japan). The eluent was evaporated to dryness and reconstituted in $200 \mu \mathrm{L}$ of $50 \%$ acetonitrile. After filtration, $50 \mu \mathrm{L}$ was automatically injected into a liquid chromatography-tandemmass spectrometry (LC-MS/MS) system. Chromatographic separation was performed with a C18 column heated at $65^{\circ} \mathrm{C}$ and a flow rate of 0.2 $\mathrm{mL} / \mathrm{min}$ (lower limit of quantification $1 \mathrm{ng} / \mathrm{mL}$, run time $3.5 \mathrm{~min}$ ). The isocratic mobile phase consisted of a mixture of $5 \% 10 \mathrm{mM}$ ammonium acetate and $0.1 \%$ acetic acid in water and $95 \% 10 \mathrm{mM}$ ammonium acetate and $0.1 \%$ acetic acid in acetonitrile. Analyses were performed in the multiple reaction monitoring mode at ion transitions $m / z 976.4{ }^{\circledR} 909.3$ for everolimus and $m / z 810.4{ }^{\circledR} 756.7$ for ascomycin. Interand intra-assay accuracies were $\pm 10 \%$ with a precision (coefficient of variation) below $5 \%$.

\section{Genotyping}

Genomic DNA was extracted from the peripheral blood of patients using NucleoSpin Blood QuickPure (Takara Bio, Kusatsu, Japan). Based on previous findings regarding pharmacogenetic determinants associated with everolimus metabolism and disposition, we examined $C Y P 3 A 4 * 22, C Y P 3 A 5 * 3$, and 
ABCG2 421C>A polymorphisms $[13,17,22]$. Genotyping was performed using TaqMan SNP genotyping assays (Thermo Fisher Scientific, Tokyo, Japan).

\section{mTOR activity in PBMCs}

PBMCs were isolated from whole blood (approximately $2 \mathrm{~mL}$ ) by Ficoll-Hypaque density gradient centrifugation. Cell counting and viability assessment were performed using the TC20 counter (Bio-Rad, Tokyo, Japan). PBMCs with viability exceeding $90 \%$ were used for the subsequent mTOR assay. After centrifugation at $400 \mathrm{xg}$ for $2 \mathrm{~min}$ at $4{ }^{\circ} \mathrm{C}$, the supernatant was discarded and the cell pellets were resuspended in $100 \mu \mathrm{L}$ of ice-cold hypotonic lysis buffer containing protease and phosphatase inhibitor cocktails (Nacalai, Kyoto, Japan), and then stored at $-80^{\circ} \mathrm{C}$ until analysis.

The mTOR activity in the extracts of PBMCs was directly measured using the Kinase-linked immunosorbent assay (K-LISA) mTOR activity kit (CBA055, Calbiochem, USA) by assessing phosphorylation of the specific mTOR substrate p70S6 kinase at Thr ${ }^{389}$, according to the manufacturer's protocol and a previous study [23]. A recombinant human mTOR enzyme (1362-end) with a specific activity of $186 \mathrm{U} / \mathrm{mg}$ (Lot\# 2052551-D, Millipore, UK) was used for calibration (standard series, 0-250 $\mathrm{ng}$ ). The protein concentration of each lysate was determined using the Coomassie Brilliant Blue R-250 Staining Solution (Bio-Rad, Tokyo, Japan) for normalization of mTOR activity. Finally, the mTOR activity in PBMCs was calculated relative to the baseline activity before the start of therapy in each patient.

\section{Outcomes}

The efficacy endpoints were progression-free survival (PFS) and overall survival (OS). For safety assessment, all adverse events were graded according to the Common Terminology Criteria for Adverse Events version 4.03. The cumulative incidence of dose-limiting toxicities (DLTs) leading to treatment discontinuation and dose interruption/reduction was estimated by adjusting for competing risks (e.g., death or treatment discontinuation due to disease progression) using the Fine and Gray model [24]. The data cutoff date was March 31, 2020.

\section{Statistical analyses}

The statistical significance of differences in non-parametric values between two groups was analyzed with the Mann-Whitney $U$ test. A receiver operating characteristic (ROC) curve was constructed, and the area under the ROC curve $\left(A U C_{R O C}\right)$ was calculated to estimate the optimal cutoff value of everolimus $\mathrm{C}_{\text {trough }}$ for predicting development of DLTs. The median PFS and OS were estimated using the KaplanMeier method, and the difference between two groups was examined using the Gehan-BreslowWilcoxon test. A two-sided $P<0.05$ was considered statistically significant. All statistical analyses were performed using STATA software, version 16 (StataCorp LLC, Texas, USA).

\section{Results}




\section{Patients and everolimus dose}

Twenty-two patients with $\mathrm{mBC}$ who were treated with everolimus plus exemestane were enrolled (Table 1). The sample included one male patient. One female patient with advanced age (80 y) started everolimus treatment at $5 \mathrm{mg} /$ day to minimize its toxic effects. Dose modifications of everolimus, specifically interruption and reduction due to DLTs, were performed in seven (32\%) patients $(n=6$ and 1 , respectively). Everolimus treatment was discontinued because of disease progression $(n=10)$, adverse events ( $n=8)$, surgery $(n=1)$, and patient refusal $(n=1)$. At the data cutoff date, everolimus therapy was ongoing in two patients. The median follow-up period was 494 days (range 102-1067 days).

\section{Everolimus pharmacokinetics/pharmacogenetics and pharmacodynamics}

Pharmacokinetic and pharmacogenetic data were available from 19 consenting patients, two of whom did not provide blood samples for determining everolimus $C_{\text {peak }}$ levels. Figure 1a shows the distribution of blood everolimus concentrations at each time point during a 24-h dosing interval at steady state in patients receiving $10 \mathrm{mg} /$ day of everolimus (total no. of observations 92 ). Overall, the maximum concentration of approximately $60 \mathrm{ng} / \mathrm{mL}$ appeared to be reached at $3 \mathrm{~h}$ post-dose, which was comparable with previous findings [25]. Large interindividual variability in $\mathrm{C}_{\text {trough }}$ was observed (8.3-36.8 $\mathrm{ng} / \mathrm{mL}$ ). Furthermore, everolimus showed considerable fluctuations in absorption, particularly within $2 \mathrm{~h}$ post-dose $\left(\mathrm{C}_{1} 7.8-107 \mathrm{ng} / \mathrm{mL}, \mathrm{C}_{2} 6.7-85.3 \mathrm{ng} / \mathrm{mL}\right)$. Among four patients receiving $5 \mathrm{mg} /$ day of everolimus due to toxicity, the median $C_{\text {peak }}$ between 1 to $2 \mathrm{~h}$ post-dose at steady state was $10 \mathrm{ng} / \mathrm{mL}$ (range 3.0-28.5 ng/mL). This was lower than the median values predicted based on $\mathrm{C}_{1}$ and $\mathrm{C}_{2}$ at a dosage of $10 \mathrm{mg} /$ day (20.7 and $27.1 \mathrm{ng} / \mathrm{mL}$, respectively), suggesting nonlinear absorption. We calculated the average $\mathrm{C}_{\text {trough }}$ and $\mathrm{C}_{\text {peak }}$ with all the respective measurements available at steady state in each patient on $10 \mathrm{mg} /$ day. No CYP3A4*22 alleles were detected in the cohort, which was consistent with a previous observation in the Japanese population [26]. Additionally, the CYP3A56986G>A and ABCG2 421C>A polymorphisms did not influence $C_{\text {trough }}$ or $C_{\text {peak }}$ (Supplementary Fig. S1).

Pharmacodynamic data on mTOR activity in PBMCs were obtained in 11 patients with evaluable samples (total no. of observations 60). A significant correlation was observed between blood everolimus concentration and mTOR activity in PBMCs relative to baseline $\left(R^{2}=0.65, P<0.0001\right.$; Fig. 1b). Notably, everolimus did not completely inhibit mTOR activity in PBMCs at therapeutic concentrations at any point during the course of everolimus treatment ( $56 \%$ maximal inhibition).

\section{Everolimus toxicity and its relationship to drug exposure}

The most frequently observed adverse event of any grade was stomatitis (77\%, Table 2). No grade 4 or 5 toxicities were reported in this study. The most common grade 3 adverse events were stomatitis and anorexia (18\% each), followed by fatigue (14\%). Grade 3 hyperglycemia was observed in one patient, whereas there were no cases of hyperlipidemia. DLTs leading to treatment discontinuation included pneumonitis $(n=4)$, stomatitis, fatigue, urticaria, and muscle pain (one patient each). One patient 
reported grade 3 dysgeusia requiring dose reduction. Dose interruption was required in patients with grade 3 non-hematological toxicities, including stomatitis and anorexia ( $n=2$ each) as well as herpes zoster and diarrhea (one patient each).

The average $\mathrm{C}_{\text {trough }}$ at steady state did not differ in patients with and without any grade of pneumonitis (median $9.4 \mathrm{ng} / \mathrm{mL}[n=3]$ and $14.0 \mathrm{ng} / \mathrm{mL}[n=16]$, respectively; $P=0.17$ ). Notably, the average $\mathrm{C}_{\text {trough }}$ was significantly higher in patients with DLTs leading to treatment discontinuation and dose interruption/reduction than in those without any DLTs ( $P=0.030 ;$ Fig. 2a). The optimal $C_{\text {trough }}$ cutoff to predict development of DLTs was $17.3 \mathrm{ng} / \mathrm{mL}\left(\mathrm{AUC}_{\mathrm{ROC}} 0.79,95 \%\right.$ confidence interval $[\mathrm{Cl}]$ 0.58-1.00; $P=$ 0.031). Furthermore, as shown in Figure $2 b$, the cumulative incidence of DLTs was significantly higher in patients with an average $C_{\text {trough }} \geq 17.3 \mathrm{ng} / \mathrm{mL}$ than in other patients (sub-hazard ratio $4.87,95 \% \mathrm{Cl} 1.53$ $15.5 ; P=0.007)$.

\section{Everolimus efficacy and its relationship to drug exposure}

The disease control rate was $45 \%$ (10/22); two patients had a partial response and eight had stable disease per the Response Evaluation Criteria for Solid Tumors (RECIST) 1.1. The median PFS and OS were 308 days ( $95 \% \mathrm{Cl} 187-355$ days) and not reached ( $95 \% \mathrm{Cl} 527$ days-not estimable), respectively (Fig. 3a). The 1-y PFS and OS rates (95\% Cl) were 18\% (3-44\%) and 90\% (65-97\%), respectively. Although not statistically significant, as shown in Figure $3 \mathrm{~b}$, the median PFS was numerically longer in patients who maintained an average steady state $C_{\text {trough }}$ below the threshold for DLTs $(17.3 \mathrm{ng} / \mathrm{mL})$ than in those who did not $(327$ days [ $95 \% \mathrm{Cl} 103-355$ days] vs 194 days [ $95 \% \mathrm{Cl} 45$ days-not estimable]; $P=$ 0.35).

\section{Discussion}

There is accumulating evidence that shows a positive relationship between everolimus exposure and clinical outcomes in oncology settings [27]. The current study provides real-world evidence to support an association between everolimus $\mathrm{C}_{\text {trough }}$ and toxicity in patients with $\mathrm{mBC}$. Deppenweiler et al. [28] previously reported that everolimus $\mathrm{C}_{\text {trough }}$ levels $>26.3 \mathrm{ng} / \mathrm{mL}$ were associated with a four-fold increased risk of adverse events in patients with a variety of cancers, with a particularly high risk in those with breast cancer. In the present study, we determined that the optimal cutoff value of everolimus $\mathrm{C}_{\text {trough }}$ for predicting the development of DLTs was $17.3 \mathrm{ng} / \mathrm{mL}$ (Fig. 2), a finding comparable to that of a previous study that identified $19.2 \mathrm{ng} / \mathrm{mL}$ as the toxicity threshold in patients with $\mathrm{mBC}$ [29]. We also found that the average $\mathrm{C}_{\text {trough }}$ at steady state did not differ between patients with and without any grade of pneumonitis. This observation is consistent with those in earlier studies demonstrating no correlation between everolimus $C_{\text {trough }}$ and the occurrence of pneumonitis $[30,31]$. Therefore, monitoring of blood everolimus concentrations may not help identify patients at increased risk of pneumonitis. Further development of reliable biomarkers in addition to serum $\mathrm{KL}-6$ levels is necessary to improve the prediction of mTOR inhibitor-induced pneumonitis [31,32]. 
Regarding the exposure-efficacy relationship, no significant difference in median PFS was reported between patients with everolimus $C_{\text {trough }}>12.6 \mathrm{ng} / \mathrm{mL}$ versus $<12.6 \mathrm{ng} / \mathrm{mL}$ who were also treated with exemestane [29]. Similarly, everolimus $\mathrm{C}_{\text {trough }}$ level was not a significant predictor of long-term efficacy in our patient cohort (Fig. 3b). These findings suggest that higher everolimus exposure will not translate into survival benefit, probably because of decreased tolerability due to toxicities such as severe stomatitis and anorexia (Table 2). Furthermore, the lack of survival benefit despite increased everolimus exposure may be explained by the fact that patients also received exemestane, which might have independently improved efficacy regardless of individual exposure to everolimus.

Overall, as shown in Fig. 1a, everolimus demonstrated variable absorption and marked variation in elimination. Although the number of patients was small, we found no indication that CYP3A56986G>A or $A B C G 2421 \mathrm{C}>\mathrm{A}$ polymorphisms influenced everolimus exposure (Supplementary Fig. S1), which is consistent with findings in previous studies [14-18]. Therefore, there may be no need to individualize the dose based on genetic polymorphisms in CYP3A5 and ABCG2. Further investigations that consider nongenetic factors (e.g., food ingredients) [33] should be conducted to clarify the mechanisms underlying the variable, potentially nonlinear pharmacokinetic characteristics of everolimus in $\mathrm{mBC}$.

In the present study, we directly measured mTOR activity in PBMCs as a marker of everolimus pharmacodynamics. Interestingly, the mTOR activity in PBMCs was not completely inhibited by everolimus at therapeutic concentrations (Fig. 1b). In a study of renal transplant recipients, Dekter et al. [23] showed similar results regarding the partial inhibition of mTOR activity by everolimus in PBMCs in vivo and in vitro. These observations may be explained by intracellular immunophilin FKBP1A potentially limiting mTOR inhibition by everolimus at high drug concentrations; this occurs with tacrolimus, which binds with the same immunophilin and incompletely inhibits calcineurin phosphatase activity at saturable concentrations [34].

Despite the fact that everolimus almost completely inhibits phosphorylation of the downstream S6 protein, partial inhibition of 4E-BP1 phosphorylation was previously observed in tumor samples and PBMCs from patients treated with everolimus $[35,36]$. Taking these findings and our results into account, partial rather than complete inhibition of the MTOR pathway by everolimus may be potentially beneficial for preventing life-threatening toxicities and/or recovering early from adverse drug reactions through dose reduction/interruption in patients receiving everolimus. Actually, no grade 4 or higher adverse events occurred in our patient cohort. On the other hand, given the fact that everolimus only partially inhibits mTOR, everolimus monotherapy might not exert adequate antitumor activity. Thus, in patients with advanced RCC who have already undergone one prior anti-angiogenic therapy, it seems reasonable to administer lenvatinib, a multikinase inhibitor, in combination with everolimus in order to increase response rates and survival [37].

Male breast cancer is a rare disease, accounting for less than $1 \%$ of all breast cancers [38]. In the present study, we enrolled one male patient with hormone receptor-positive, HER2-negative $\mathrm{mBC}$ who was treated with everolimus plus exemestane. Ten days after the start of therapy, the patient visited the emergency 
room because of severe fatigue, leading to immediate discontinuation of everolimus treatment. On that day, the blood everolimus concentration more than $24 \mathrm{~h}$ after the last dose was $18.4 \mathrm{ng} / \mathrm{mL}$, which was above the toxicity threshold identified in this study $(17.3 \mathrm{ng} / \mathrm{mL})$. The patient was subsequently treated with exemestane alone followed by high-dose toremifene, which was finally discontinued due to disease progression 5.5 months after he began receiving everolimus plus exemestane. Among patients with breast cancer, men had a numerically higher incidence of adverse events than women during everolimus treatment in real-world practice [39]. Potential gender differences in the exposure-toxicity relationship for everolimus should be investigated in a large population-based study that includes male patients with $\mathrm{mBC}$.

Limitations of this study include its small sample size, lack of robust pharmacokineticpharmacodynamic profiling, and single-center design. Despite these limitations, the present study demonstrated that increased exposure to everolimus was associated with an increased risk of DLTs among patients with $\mathrm{mBC}$. Through TDM, pharmacokinetically guided dosing of everolimus in routine clinical practice may help avoid the development of DLTs and improve efficacy as well as adherence to treatment in patients who receive everolimus for $\mathrm{mBC}$.

\section{Conclusions}

The present study indicates that everolimus may exert antitumor activity without completely inhibiting mTOR activity in patients with $\mathrm{mBC}$. Furthermore, our results suggest that the potential upper threshold for the therapeutic window of everolimus $C_{\text {trough }}$ is $17.3 \mathrm{ng} / \mathrm{mL}$, warranting further prospective investigation in a larger patient population.

\section{Declarations}

\section{Acknowledgements:}

We thank all patients and medical staff who contributed to this study.

Funding: This work was supported in part by a grant from the Japan Society for the Promotion of Science (JSPS) KAKENHI (No. 16K08902) and a grant from the Japan Research Foundation for Clinical Pharmacology.

Conflicts of interest: None to declare.

Ethics approval and consent to participate: The protocol of this study was approved by the institutional ethics committee of Asahikawa Medical University (\#14085). The study was performed in accordance with the Declaration of Helsinki and its amendments. Written informed consent was obtained from each patient prior to participation in the study.

Consent for publication: All authors approved the final version of the manuscript. 
Availability of data and material: The data supporting the findings of this study are available on request from the corresponding author. The data are not publicly available because of privacy or ethical restrictions.

Author contributions: Study concept and design: M.F., M.K.; acquisition, analysis, or interpretation of data: all authors; drafting of the manuscript: M.F.; critical revision of the manuscript for important intellectual content: all authors; statistical analysis: M.F.; acquisition of funding: M.F.; administrative, technical, or material support: K.I., M.K.; supervision: M.F.

\section{Compliance with Ethical Standards}

Disclosure of potential conflicts of interest: All authors have no conflicts of interest to declare.

Research involving human participants: The protocol of this study was approved by the institutional ethics committee of Asahikawa Medical University (\#14085). The study was performed in accordance with the Declaration of Helsinki and its amendments.

Informed consent: Written informed consent was obtained from each patient prior to enrollment.

\section{References}

1. Budde K, Becker T, Arns W, Sommerer C, Reinke P, Eisenberger U, Kramer S, Fischer W, Gschaidmeier H, Pietruck F, ZEUS Study Investigators (2011) Everolimus-based, calcineurin-inhibitor-free regimen in recipients of de-novo kidney transplants: an open-label, randomised, controlled trial. Lancet 377:837-847

2. Motzer RJ, Escudier B, Oudard S, Hutson TE, Porta C, Bracarda S, Grünwald V, Thompson JA, Figlin RA, Hollaender N, Urbanowitz G, Berg WJ, Kay A, Lebwohl D, Ravaud A, RECORD-1 Study Group (2008) Efficacy of everolimus in advanced renal cell carcinoma: a double-blind, randomised, placebocontrolled phase III trial. Lancet 372:449-456

3. Yao JC, Shah MH, Ito T, Bohas CL, Wolin EM, Van Cutsem E, Hobday TJ, Okusaka T, Capdevila J, de Vries EG, Tomassetti P, Pavel ME, Hoosen S, Haas T, Lincy J, Lebwohl D, Öberg K; RAD001 in Advanced Neuroendocrine Tumors, Third Trial (RADIANT-3) Study Group (2011) Everolimus for advanced pancreatic neuroendocrine tumors. N Engl J Med 364:514-523

4. Franz DN, Belousova E, Sparagana S, Bebin EM, Frost M, Kuperman R, Witt O, Kohrman MH, Flamini JR, Wu JY, Curatolo P, de Vries PJ, Whittemore VH, Thiele EA, Ford JP, Shah G, Cauwel H, LebwohI D, Sahmoud T, Jozwiak S (2013) Efficacy and safety of everolimus for subependymal giant cell astrocytomas associated with tuberous sclerosis complex (EXIST-1): a multicentre, randomised, placebo-controlled phase 3 trial. Lancet 381:125-132

5. Bissler JJ, Kingswood JC, Radzikowska E, Zonnenberg BA, Frost M, Belousova E, Sauter M, Nonomura N, Brakemeier S, de Vries PJ, Whittemore VH, Chen D, Sahmoud T, Shah G, Lincy J, Lebwohl D, Budde K (2013) Everolimus for angiomyolipoma associated with tuberous sclerosis 
complex or sporadic lymphangioleiomyomatosis (EXIST-2): a multicentre, randomised, double-blind, placebo-controlled trial. Lancet 381:817-824

6. Baselga J, Campone M, Piccart M, Burris HA 3rd, Rugo HS, Sahmoud T, Noguchi S, Gnant M, Pritchard KI, Lebrun F, Beck JT, Ito Y, Yardley D, Deleu I, Perez A, Bachelot T, Vittori L, Xu Z, Mukhopadhyay P, Lebwohl D, Hortobagyi GN (2012) Everolimus in postmenopausal hormonereceptor-positive advanced breast cancer. N Engl J Med 366:520-529

7. Kovarik JM, Kahan BD, Kaplan B, Lorber M, Winkler M, Rouilly M, Gerbeau C, Cambon N, Boger R, Rordorf C, Everolimus Phase 2 Study Group (2001) Longitudinal assessment of everolimus in de novo renal transplant recipients over the first post-transplant year: pharmacokinetics, exposureresponse relationships, and influence on cyclosporine. Clin Pharmacol Ther 69:48-56

8. Kovarik JM, Tedesco H, Pascual J, Civati G, Bizot MN, Geissler J, Schmidli H (2004) Everolimus therapeutic concentration range defined from a prospective trial with reduced-exposure cyclosporine in de novo kidney transplantation. Ther Drug Monit 26:499-505

9. Franz DN, Belousova E, Sparagana S, Bebin EM, Frost M, Kuperman R, Witt O, Kohrman MH, Flamini JR, Wu JY, Curatolo P, de Vries PJ, Berkowitz N, Anak O, Niolat J, Jozwiak S (2014) Everolimus for subependymal giant cell astrocytoma in patients with tuberous sclerosis complex: 2-year open-label extension of the randomised EXIST-1 study. Lancet Oncol 15:1513-1520

10. Kirchner GI, Meier-Wiedenbach I, Manns MP (2004) Clinical pharmacokinetics of everolimus. Clin Pharmacokinet 43:83-95

11. Crowe A, Lemaire M (1998) In vitro and in situ absorption of SDZ-RAD using a human intestinal cell line (Caco-2) and a single pass perfusion model in rats: comparison with rapamycin. Pharm Res 15:1666-1672

12. Chu C, Abbara C, Noël-Hudson MS, Thomas-Bourgneuf L, Gonin P, Farinotti R, Bonhomme-Faivre L (2009) Disposition of everolimus in mdr1a-/1b- mice and after a pre-treatment of lapatinib in Swiss mice. Biochem Pharmacol 77:1629-1634

13. Minocha M, Khurana V, Qin B, Pal D, Mitra AK (2012) Co-administration strategy to enhance brain accumulation of vandetanib by modulating P-glycoprotein (P-gp/Abcb1) and breast cancer resistance protein (Bcrp1/Abcg2) mediated efflux with m-TOR inhibitors. Int J Pharm 434:306-314

14. Lemaitre F, Bezian E, Goldwirt L, Fernandez C, Farinotti R, Varnous S, Urien S, Antignac M (2012) Population pharmacokinetics of everolimus in cardiac recipients: comedications, ABCB1, and CYP3A5 polymorphisms. Ther Drug Monit 34:686-694

15. Moes DJ, Press RR, den Hartigh J, van der Straaten T, de Fijter JW, Guchelaar HJ (2012) Population pharmacokinetics and pharmacogenetics of everolimus in renal transplant patients. Clin Pharmacokinet 51:467-480

16. Schoeppler KE, Aquilante CL, Kiser TH, Fish DN, Zamora MR (2014) The impact of genetic polymorphisms, diltiazem, and demographic variables on everolimus trough concentrations in lung transplant recipients. Clin Transplant 28:590-597 
17. Moes DJ, Swen JJ, den Hartigh J, van der Straaten T, van der Heide JJ, Sanders JS, Bemelman FJ, de Fijter JW, Guchelaar HJ (2014) Effect of CYP3A4*22, CYP3A5*3, and CYP3A combined genotypes on cyclosporine, everolimus, and tacrolimus pharmacokinetics in renal transplantation. CPT Pharmacometrics Syst Pharmacol 3:e100

18. Picard N, Rouguieg-Malki K, Kamar N, Rostaing L, Marquet P (2011) CYP3A5 genotype does not influence everolimus in vitro metabolism and clinical pharmacokinetics in renal transplant recipients. Transplantation 91:652-656

19. Schuler W, Sedrani R, Cottens S, Häberlin B, Schulz M, Schuurman HJ, Zenke G, Zerwes HG, Schreier MH (1997) SDZ RAD, a new rapamycin derivative: pharmacological properties in vitro and in vivo. Transplantation 64:36-42

20. Zou Z, Tao T, Li H, Zhu X (2020) mTOR signaling pathway and mTOR inhibitors in cancer: progress and challenges. Cell Biosci 10:31

21. Peralba JM, DeGraffenried L, Friedrichs W, Fulcher L, Grünwald V, Weiss G, Hidalgo M (2003) Pharmacodynamic evaluation of $\mathrm{CCl}-779$, an inhibitor of mTOR, in cancer patients. Clin Cancer Res 9:2887-2892

22. Tang SC, Sparidans RW, Cheung KL, Fukami T, Durmus S, Wagenaar E, Yokoi T, van Vlijmen BJ, Beijnen JH, Schinkel AH (2014) P-glycoprotein, CYP3A, and plasma carboxylesterase determine brain and blood disposition of the mTOR Inhibitor everolimus (Afinitor) in mice. Clin Cancer Res 20:31333145

23. Dekter HE, Romijn FP, Temmink WP, van Pelt J, de Fijter JW, Smit NP (2010) A spectrophotometric assay for routine measurement of mammalian target of rapamycin activity in cell lysates. Anal Biochem 403:79-87

24. Fine JP, Gray RJ (1999) A proportional hazards model for the subdistribution of a competing risk. J Am Stat Assoc 94:496-509

25. Okamoto I, Doi T, Ohtsu A, Miyazaki M, Tsuya A, Kurei K, Kobayashi K, Nakagawa K (2010) Phase I clinical and pharmacokinetic study of RAD001 (everolimus) administered daily to Japanese patients with advanced solid tumors. Jpn J Clin Oncol 40:17-23

26. Okubo M, Murayama N, Shimizu M, Shimada T, Guengerich FP, Yamazaki H (2013) CYP3A4 intron 6 $\mathrm{C}>\mathrm{T}$ polymorphism (CYP3A4*22) is associated with reduced CYP3A4 protein level and function in human liver microsomes. J Toxicol Sci 38:349-354

27. Falkowski S, Woillard JB (2019) Therapeutic drug monitoring of everolimus in oncology: evidences and perspectives. Ther Drug Monit 41:568-574

28. Deppenweiler M, Falkowski S, Saint-Marcoux F, Monchaud C, Picard N, Laroche ML, Tubiana-Mathieu N, Venat-Bouvet L, Marquet P, Woillard JB (2017) Towards therapeutic drug monitoring of everolimus in cancer? Results of an exploratory study of exposure-effect relationship. Pharmacol Res 121:138144

29. Willemsen AECAB, de Geus-Oei LF, de Boer M, Tol J, Kamm Y, de Jong PC, Jonker MA, Vos AH, Grootjans W, de Groot JWB, Mulder SF, Aarntzen EHJG, Gerritsen WR, van Herpen CML, van Erp NP 
(2018) Everolimus exposure and early metabolic response as predictors of treatment outcomes in breast cancer patients treated with everolimus and exemestane. Target Oncol 13:641-648

30. de Wit D, Schneider TC, Moes DJ, Roozen CF, den Hartigh J, Gelderblom H, Guchelaar HJ, van der Hoeven JJ, Links TP, Kapiteijn E, van Erp NP (2016) Everolimus pharmacokinetics and its exposuretoxicity relationship in patients with thyroid cancer. Cancer Chemother Pharmacol 78:63-71

31. Willemsen AECAB, Tol J, van Erp NP, Jonker MA, de Boer M, Meek B, de Jong PC, van Moorsel C, Gerritsen WR, Grutters JC, van Herpen CML (2019) Prospective study of drug-induced interstitial lung disease in advanced breast cancer patients receiving everolimus plus exemestane. Target Oncol 14:441-451

32. Willemsen AE, Grutters JC, Gerritsen WR, van Erp NP, van Herpen CM, Tol J (2016) mTOR inhibitorinduced interstitial lung disease in cancer patients: comprehensive review and a practical management algorithm. Int J Cancer 138:2312-2321

33. Kovarik JM, Hartmann S, Figueiredo J, Rordorf C, Golor G, Lison A, Budde K, Neumayer HH (2002) Effect of food on everolimus absorption: quantification in healthy subjects and a confirmatory screening in patients with renal transplants. Pharmacotherapy 22:154-159

34. Kung L, Halloran PF (2000) Immunophilins may limit calcineurin inhibition by cyclosporine and tacrolimus at high drug concentrations. Transplantation 70:327-335

35. Tabernero J, Rojo F, Calvo E, Burris H, Judson I, Hazell K, Martinelli E, Ramon y Cajal S, Jones S, Vidal L, Shand N, Macarulla T, Ramos FJ, Dimitrijevic S, Zoellner U, Tang P, Stumm M, Lane HA, Lebwohl D, Baselga J (2008) Dose- and schedule-dependent inhibition of the mammalian target of rapamycin pathway with everolimus: a phase I tumor pharmacodynamic study in patients with advanced solid tumors. J Clin Oncol 26:1603-1610

36. Wright KD, Yao X, London WB, Kao PC, Gore L, Hunger S, Geyer R, Cohen KJ, Allen JC, Katzenstein HM, Smith A, Boklan J, Nazemi K, Trippett T, Karajannis M, Herzog C, Destefano J, Direnzo J, Pietrantonio J, Greenspan L, Cassidy D, Schissel D, Perentesis J, Basu M, Mizuno T, Vinks AA, Prabhu SP, Chi SN, Kieran MW (2021) A POETIC Phase Il study of continuous oral everolimus in recurrent, radiographically progressive pediatric low-grade glioma. Pediatr Blood Cancer 68:e28787

37. Motzer RJ, Hutson TE, Glen H, Michaelson MD, Molina A, Eisen T, Jassem J, Zolnierek J, Maroto JP, Mellado B, Melichar B, Tomasek J, Kremer A, Kim HJ, Wood K, Dutcus C, Larkin J (2015) Lenvatinib, everolimus, and the combination in patients with metastatic renal cell carcinoma: a randomised, phase 2, open-label, multicentre trial. Lancet Oncol 16:1473-1482

38. White J, Kearins O, Dodwell D, Horgan K, Hanby AM, Speirs V (2011) Male breast carcinoma: increased awareness needed. Breast Cancer Res 13:219

39. Sharma M, Duan Z, Zhao H, Giordano SH, Chavez-MacGregor M (2020) Real-world patterns of everolimus use in patients with metastatic breast cancer. Oncologist 25:937-942

\section{Tables}

Table 1 Patient characteristics 


\begin{tabular}{|ll|}
\hline Characteristic & N=22 \\
\hline Sex, male/female, $n(\%)$ & $1 / 21(5 / 95)$ \\
\hline Age, median (range), years & $67(36-80)$ \\
\hline Body weight, median (range), kg & $56(39-73)$ \\
\hline ECOG performance status, $n(\%)$ & \\
\hline 0 & $19(86)$ \\
\hline 1 & $3(14)$ \\
\hline Number of previous therapies, $n(\%)$ & \\
\hline 1 & $4(18)$ \\
\hline 2 & $5(23)$ \\
\hline 33 & $12(55)$ \\
\hline Unknown & $1(5)$ \\
\hline Sites of metastases, $n(\%)$ & \\
\hline Bone & $16(73)$ \\
\hline Lung & $11(50)$ \\
\hline Liver & $9(41)$ \\
\hline Brain & $2(9)$ \\
\hline Number of metastatic sites, $n(\%)$ & \\
\hline 1 & $7(23)$ \\
\hline 2 & $7(32)$ \\
\hline 33 & \\
\hline
\end{tabular}

ECOG Eastern Cooperative Oncology Group

Table 2 Adverse events 


\begin{tabular}{|lll|}
\hline Toxicity & $\begin{array}{l}\text { Any grade } \\
\text { (\%) }\end{array}$ & $\begin{array}{l}\text { Grade 3 } \\
\text { (\%) }\end{array}$ \\
\hline Stomatitis & 77 & 18 \\
\hline Leukopenia & 45 & 0 \\
\hline Fatigue & 23 & 14 \\
\hline Anorexia & 18 & 18 \\
\hline Diarrhea & 18 & 5 \\
\hline Dysgeusia & 18 & 5 \\
\hline Hyperglycemia & 18 & 5 \\
\hline Pneumonitis & 18 & 5 \\
\hline Rash & 18 & 0 \\
\hline Paronychia & 14 & 0 \\
\hline AST increased & 9 & 0 \\
\hline g-GTP increased & 5 & 5 \\
\hline Herpes zoster & 5 & 5 \\
\hline Dry mouth & 5 & 0 \\
\hline Dry skin & 5 & 0 \\
\hline Hand-foot syndrome & 5 & 0 \\
\hline Pruritus & 5 & 0 \\
\hline Urticaria & 5 & 0 \\
\hline
\end{tabular}

AST aspartate aminotransferase, $g$-GTP g-glutamyl transpeptidase

Figures 
a

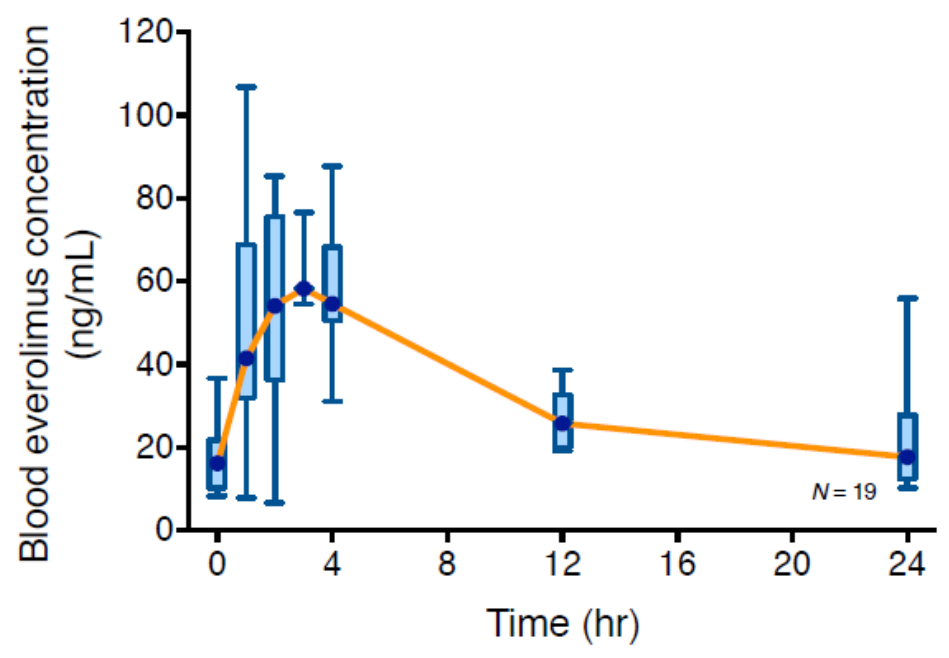

b

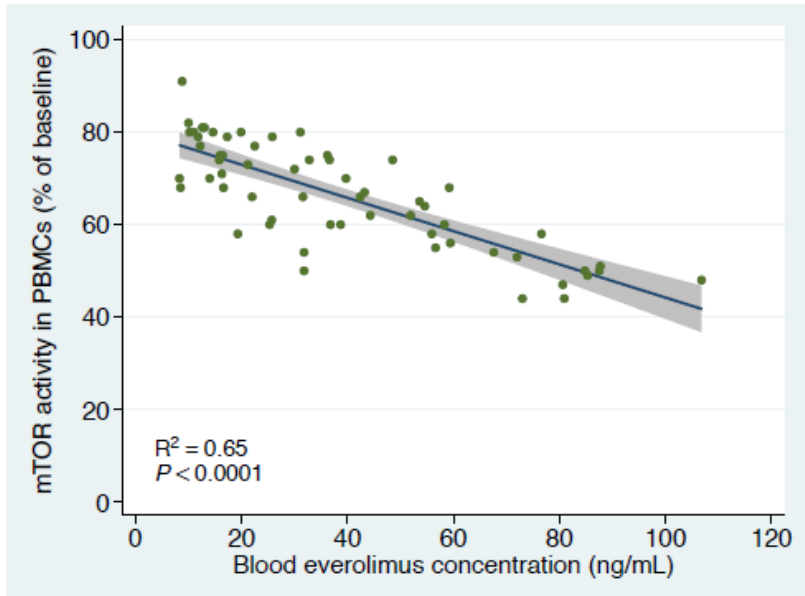

Figure 1

a Blood everolimus concentration-time profile in 19 patients. The box within the plot area indicates the median (circle) and the interquartile range of the data, with whiskers representing the minimum and maximum values. The medians are chronologically connected. $b$ Correlation between blood everolimus concentration and the mammalian target of rapamycin (mTOR) activity in peripheral blood mononuclear cells (PBMCs). The grey bands around the regression line represent the $95 \%$ confidence intervals.

a

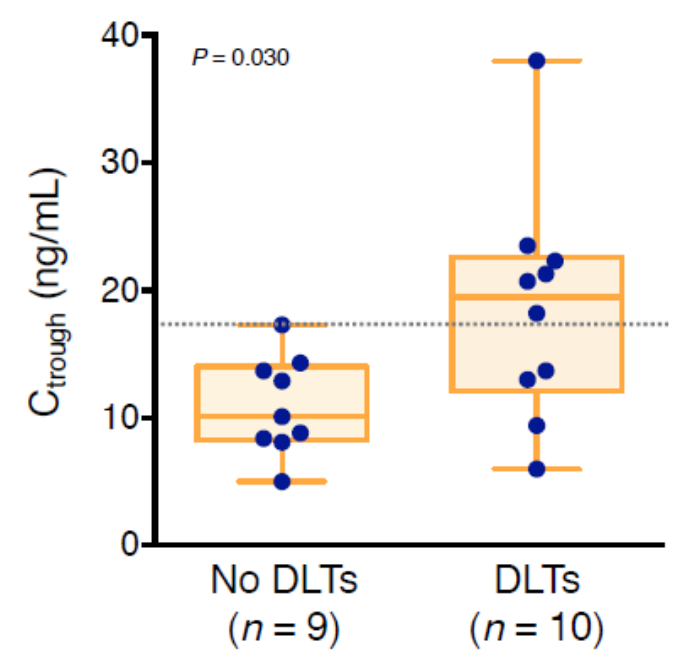

b

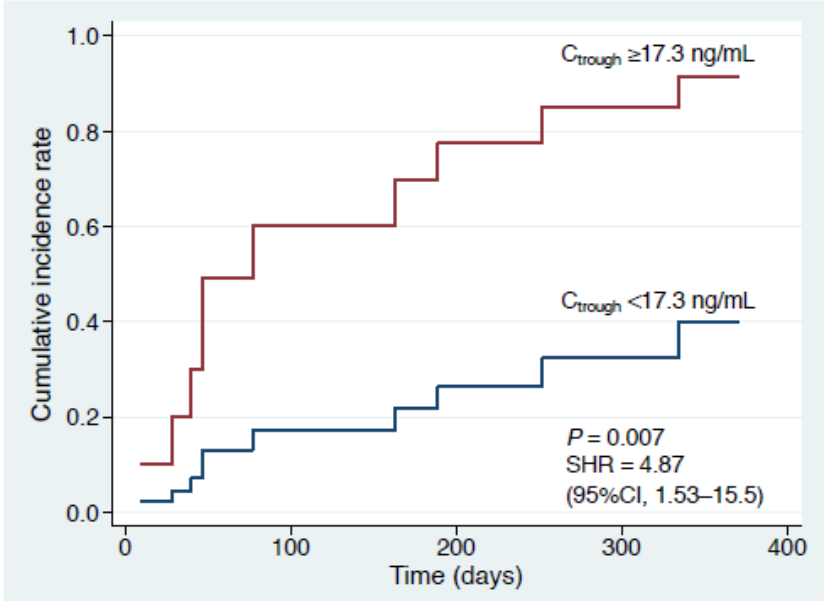

Figure 2

a Association between the average everolimus trough concentration (Ctrough) at steady state and the development of dose-limiting toxicities (DLTs). The boxes indicate the median and the interquartile range of the data; the whiskers represent the minimum and maximum values. The horizontal dotted line 
indicates the optimal cutoff value $(17.3 \mathrm{ng} / \mathrm{mL})$ to predict the development of DLTs, as estimated by a receiver operating characteristic curve analysis. b Cumulative incidence of DLTs according to the average Ctrough at steady state. $\mathrm{Cl}$ confidence interval, SHR sub-hazard ratio

a

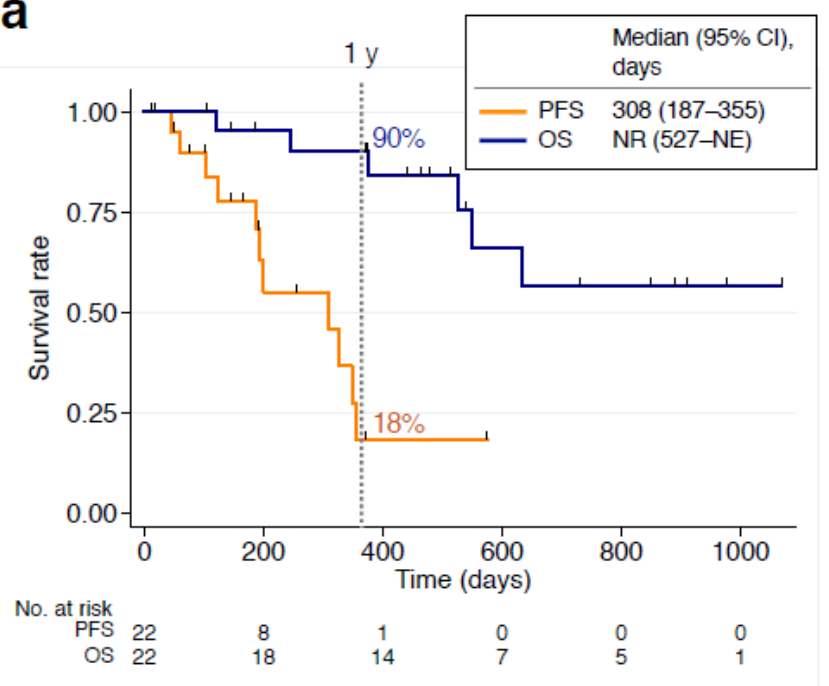

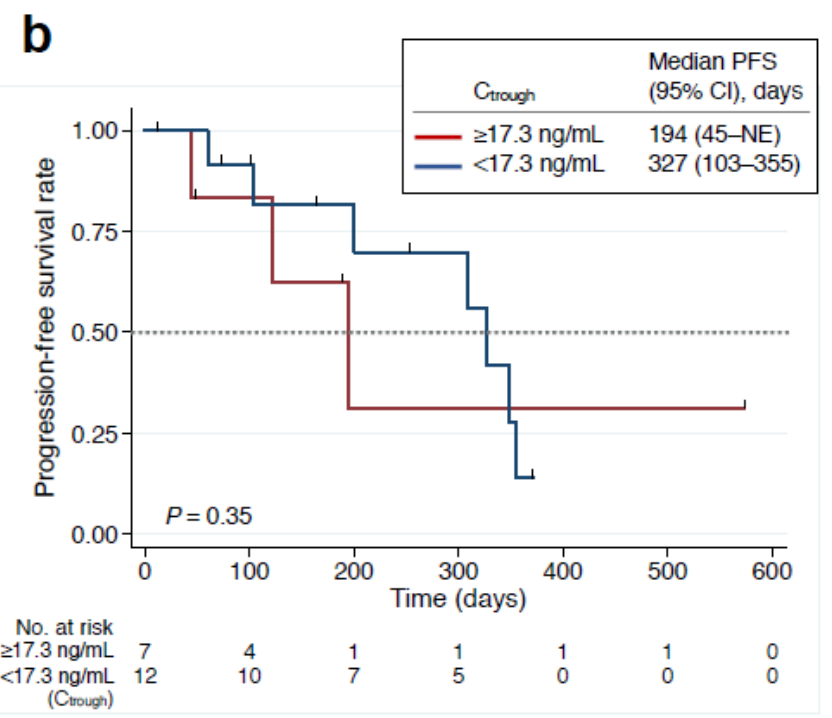

b

$\begin{array}{cccccccc}17.3 \mathrm{ng} / \mathrm{mL} & 7 & 4 & 1 & 1 & 1 & 1 & 0 \\ 17.3 \mathrm{ng} / \mathrm{mL} & 12 & 10 & 7 & 5 & 0 & 0 & 0\end{array}$

\section{Figure 3}

a Progression-free survival (PFS) and overall survival (OS). b PFS according to the average everolimus trough concentration (Ctrough) at steady state. $\mathrm{Cl}$ confidence interval, NE not estimable, NR not reached 